\title{
ЦИТИРОВАНИЕ В РЕЧИ УЧИТЕЛЯ КАК ПРОФЕССИОНАЛЬНО ЗНАЧИМЫЙ АСПЕКТ КОММУНИКАТИВНОЙ ПЕДАГОГИЧЕСКОЙ ПРАКТИКИ
}

\author{
Любовь Гордеева \\ QUOTING IN A TEACHER'S SPEECH AS A PROFESSIONALLY SIGNIFICANT \\ ASPECT OF COMMUNICATIVE PEDAGOGICAL PRACTICE
}

\author{
Lyubov Gordeeva
}

\begin{abstract}
Резюме: В статье рассматривается специфика использования цитат в речи учителя. Особое внимание обращается на обоснование репродуктивной основы коммуникативной практики педагога и профессиональный характер цитирования (дословного воспроизведения) чужих высказываний в учебноречевых ситуациях. В работе также представлена обзорная характеристика жанровых разновидностей цитат, востребованных в речевой деятельности преподавателя.
\end{abstract}

Ключевые слова: речевая практика учителя, чужая речь, репродуктивные высказывания педагога, цитирование, цитата, жанровые разновидности цитат.

Abstract: The article discusses the specifics of using quotes in the teacher's speech. Special attention is paid to the substantiation of the reproductive basis of the teacher's communicative practice and the professional nature of quoting (verbatim reproduction) of other people's statements in educational and speech situations. The paper also provides an overview of the genre varieties of quotations that are in demand in the teacher's speech activity.

Key words: teacher's speech practice, foreign speech, teacher's reproductive utterances, quoting, quotation, genre varieties of quotations.

DOI: $10.14712 / 9788076032088.4$

Профессиональная практика учителя традиционно связывается с понятием репродуктивной речевой деятельности. Очевидным является факт, что учитель, готовясь к урокам, зачастую использует уже известные в науке сведения, адаптируя их к уровню знаний и особенностям психологического и возрастного развития учеников. Это позволяет назвать профессиональную речь учителя репродуктивной, то есть воспроизводящей содержание чужих источников (научных, учебно-научных, публицистических, художественных и др.). Однако степень изменения «готовых» учебных сведений, преподносимых учителем на уроке, зависит от образовательных задач занятия, личной заинтересованности и уровня творческой активности самого педагога. В связи с этим мы можем утверждать, что воспроизводящая речевая практика преподавателя может носить как репродуктивный, так и репродуктивно-продуктивный характер, в зависимости от степени творческого преобразования информации, используемой педагогом на уроках. Этот факт позволил нам определить профессионально значимый характер такого научного феномена, как чужая речь, под которой, на основании научного обзора работ Н.Б. Агранович, Н.Д. Арутюновой, Н.А. Баляковой, М.М. Бахтина, В.В. Дементьева, Н.Д. Десяевой, Ю.Н. Караулова, Е.А. Клякиной, В.И. Кодухова, С.В. Коростовой, И.В. Лыткиной, Н.В. Максимовой, В.Н. Мещерякова, С.Н. Молодцовой и др., мы понимаем любые высказывания, не 
принадлежащие учителю и введенные в индивидуально-авторский текст дословно или в виде пересказа. Дословное введение чужой информации в речь адресанта традиционно называется цитированием (Арутюнова 1999, Караулов 2004, Кодухов 1957), а недословное использование чужих сведений, выраженное в изменении содержания, структуры, композиции и стилистических особенностей текста-первоисточника, - пересказом (Мещеряков 2002).

В рамках данной статьи мы более подробно рассмотрим особенности профессионально значимого цитирования в речи учителя, а также разнообразный жанровый репертуар дословных высказываний педагога.

Начнем с определения термина «цитата». Как правило, ученые-лингвисты определяют цитату как дословную выдержку из какого-либо текста, источника (Арутюнова 1999, Лукин 2005, Сидоренко 1995, Чернец 2004). При этом в узком понимании цитатой называют только точно воспроизведенные, т.е. не допускающие искажений фрагменты чужого высказывания, малоизвестные адресату, а следовательно, требующие необходимой ссылки на первоисточник. В широком же значении к цитатам относят любой элемент первоисточника, который введен в авторский текст дословно или с незначительными изменениями лексико-синтаксического характера, что позволяет адресанту воспроизводить фрагменты любого объема, не опасаясь за изменение языкового материала (Чернец 2004). В данном случае к цитатам можно отнести так называемые прецедентные, общеизвестные, высказывания, жанровый репертуар которых вбирает в себя тексты различного объема и содержания (от афоризма до притчи, легенды и предания) (Чернец 2004, 478). Отметим, что мы в своей работе придерживаемся широкого понимания цитаты, а следовательно, включаем в ее состав а) собственно цитаты, т.е. неизвестные или мало известные широкому кругу адресатов высказывания, а следовательно, требующие обязательной ссылки на первоисточник; б) эпиграфы; в) прецедентные (популярные, общеизвестные) тексты и г) клишированные педагогические высказывания, воспроизводящиеся на основе известного в педагогической практике образца (см. примеры далее).

В связи с дословной передачей содержания чужих источников, в науке выделяют так называемые приемы введения цитат, то есть особые признаки, указывающие на факт присутствия в речи адресанта чужого высказывания. Данные признаки можно "распознать» (обнаружить) как в устной, так и в письменной коммуникативной практике педагога. Так, например, в устной речи цитата, как правило, выделяется интонацией и специфическими языковыми средствами (вводными конструкциями, авторскими словами в предложениях с прямой речью, главным предложением в конструкциях с косвенной речью, перформативными глаголами). Стилистическое разнообразие используемых в речи учителя, особенно словесника, цитат очевидно. Нередко он обращается к цитатам из научной (учебно-научной), публицистической и художественной литературы, что связано с необходимостью «...точно, без искажения воспроизвести тот или иной фрагмент первоисточника, а следовательно, доказать, аргументировать, украсить свое высказывание, сформировать представление учеников о речевой и творческой личности мастера слова, охарактеризовать эпоху, используя для этого высказывания поэтов и прозаиков» (Гордеева 2012, 46). В связи с этим можно заключить, что цитата в педагогической речи, как правило, выполняет две главные функции - информативную (с учетом возможностей аргументации) и фатическую (эмоциональную), представляющую школьникам учебные сведения в яркой и образной форме, что зачастую вызывает необходимый эмоциональный отклик. Приведем пример. 


\section{Фрагмент для анализа №1}

<...> Рассмотрим линию Катерины и ее возлюбленного Бориса. Сначала попытаемся понять, почему героиня полюбила этого человека. Ответ можно найти в статье $\mathrm{H}$. Добролюбова. Он объяснял это так: «В этой страсти заключается для нее вся жизнь; вся сила ее натуры, все ее живые стремления сливаются здесь. К Борису влечет ее не одно то, что он ей нравится, что он и с виду и по речам не похож на остальных окружающих ее, к нему влечет ее и потребность любви, не нашедшая себе отзыва в муже, и оскорбленное чувство жены и женщины, и смертельная тоска ее однообразной жизни, и желание воли, простора, горячей, беззапретной свободы.» Это мнение известного критика-публициста. $A$ теперь найдите подтверждение или опровержение этому в монологе самой героини <...> (фрагмент сообщающего монолога учителя).

В данном случае профессиональное использование цитаты, введенной в речь учителя с помощью авторских слов, обусловлено не только необходимостью информирования учеников о причинах зарождения чувств Катерины к Борису, но и важностью выразительной характеристики ее состояния с помощью тропов и риторических фигур: «вся жизнь; вся сила ее натуры, все ее живые стремления» - асиндетон; «и оскорбленное чувство жены и женшины, и смертельная тоска ее однообразной жизни, и желание воли, простора, горячей, беззапретной свободы» - полисиндетон, градация; “смертельная тоска», "живые стремления», «горячая, беззапретная свобода» - эпитеты и т.д. При этом коммуникативное намерение учителя данными задачами не исчерпывается: введение цитаты подталкивает учеников к дальнейшим размышлениям на данную тему. Именно поэтому педагог просит школьников найти подтверждение словам критика в монологе главной героини. В результате, можно заключить, что цитата в речи учителя, как правило, выполняет комплексную коммуникативную задачу (Гордеева 2012, 47).

Кроме публицистических и художественных источников, учитель может обращаться к цитированию фрагментов из учебников, методических и учебных пособий, откуда в качестве цитат, как правило, заимствуются вопросы для обсуждения, установки на различные виды речевой деятельности, правила и определения, формулировки заданий к выполнению упражнений и т.д. При этом их искажение может привести к нарушению принципа научности, то есть разрушению соответствующих действительности предметных представлений, а также неправильному инструктированию, а следовательно, непониманию школьниками алгоритма интеллектуально-речевых действий. В данном случае дословность воспроизведения чужой информации имеет принципиальное значение. Приведем примеры подобного цитирования.

Фрагмент для анализа №2

<...> Ребята, ваша задача сейчас - прочитать и озаглавить текст. Далее вам необходимо выписать предложения с прямой речью и построить их схемы. После этого укажите предложения с однородными членами. Объясните постановку знаков препинания между ними ${ }^{1}<\ldots>$ (фрагмент инструктирующего монолога учителя).

Фрагмент для анализа №3

Итак, что мы с вами выяснили о подлежащем? Во-первых, подлежащее - это главный член предложения, который обозначает предмет речи и отвечает на вопросы именительного падежа кто? что? Во-вторых, оно может быть выражено разными частями речи, а также цельным словосочетанием, то есть синтаксически неразложимым

\footnotetext{
${ }^{1}$ Шрифтом выделены фрагменты неточной цитаты.
} 
сочетанием, выполняющим в предложении одну и ту же синтаксическую функцию <...> (фрагмент обобщающего монолога учителя).

В данном случае в первом фрагменте учитель, изменив грамматическую форму нескольких глаголов (в первоисточнике: «прочитайте», «озаглавьте», «выпишите», «постройте»), дословно воспроизводит из учебника по русскому языку (Баранов 2006, 16) инструкцию к выполнению задания с целью точно обозначить условия выполнения упражнения, а во втором, подводя итоги урока, - с точностью воспроизводит определения лингвистических терминов (Бабайцева 2006,28$)$ для обобщения и закрепления знаний учащихся об изучаемом понятии. Как правило, такие цитаты вводятся учителем в педагогический монолог самостоятельно (без специфических языковых конструкций) и составляют основной массив дословных высказываний педагога. По нашим наблюдениям, в таких случаях часто используется явление точной или неточной цитации, когда фрагменты первоисточника воспроизводятся в соответствии с формулировкой учебника либо с незначительными изменениями на грамматическом уровне, например: глагол в повелительном наклонении заменяется на инфинитив («Прочитайте и перескажите текст...» (исходный вариант) - «Ваша задача прочитать и пересказать текст...» (вариант учителя)); существительное в именительном падеже - на существительное в винительном или творительном падежах («Имя числительное это самостоятельная часть речи, которая... (исходный вариант) - «Именем числительным называют самостоятельную часть речи, которая...” (вариант учителя)). Однако основное содержательное ядро цитат, как правило, остается дословно воспроизведенным, с сохранением особенностей лексико-грамматического состава. Зачастую использование таких высказываний заранее планируется учителем, за исключением так называемых прецедентных высказываний, которые составляют особую группу цитат в речи педагога и характеризуются учеными как разновидность чужой речи, которая вносит в педагогический монолог содержательновыразительный аспект (Лыткина 2003, 6). Приведем пример.

\section{Фрагмент для анализа №4}

Ребята / сегодня у нас с вами будет не совсем обычное занятие / руководствуясь картой / мы совершим путешествие по городу Деепричастие и посетим его главные улицы // Начнем мы с самого известного места в городе / проспекта Теоретического // В прочессе беседы вам необходимо будет вспомнить самые важные сведения о деепричастии / стараясь отвечать на вопросы учителя с чувством / с толком / с расстановкой ${ }^{2}$ чтообы не утомлять и не вводить его в заблуждение // Кроме этого / мы зайдем на площадь Словообразования / где восстановим в памяти процесс образования деепричастий // Затем мы плавно перейдем на улицы Орфографическая и Пунктуационная / где закрепим наши знания об особенностях написания частицы HE $c$ деепричастиями и постановки знаков препинания при деепричастном обороте // Последний пункт нашего путешествия / площадь Стилистическая // Здесь мы будем совершенствовать умение правильно употреблять деепричастия в речи // Итак / в путь // (фрагмент стенограммы видеозаписи реального урока, вводный монолог учителя).

В данной ситуации во вводном монологе, основанном на обобщении изученного, учитель использовал известное выражение из комедии А.С. Грибоедова «Горе от ума» с целью эмоционально подготовить учеников к предстоящей работе и в то же время посоветовать им, как нужно строить свой ответ. Можно предположить, что обращение к данному прецедентному

\footnotetext{
${ }^{2}$ Шрифтом выделено общеизвестное высказывание.
} 
тексту заранее учителем не планировалось, а было использовано ситуативно с целью реализовать комплексную педагогическую задачу. Подобные случаи, включая эмоционально сложные педагогические ситуации (конфликтные или требующие обязательного воспитательного вмешательства) нередко ставят учителя в положение сиюминутного реагирования и/или нестандартного решения проблемы с помощью известных речевых формул. Этим можно объяснить широкий научный интерес к особенностям их функционирования и использования.

Опыт реферирования научных источников (Арбузова 2007, Банникова 2004, Исаева 2001, Караулов 2004, Костомаров 1994, Лыткина 2003, Наумова 2003, Слышкин 2000, щурина 2004) показал, что впервые термин «прецедентный текст» был употреблен Ю. Н. Карауловым, который определил его значение через слово «прецедент», т. е. «случай, имевший место ранее и служащий образцом для сходных случаев» (Москвин 2006, 536). На сегодняшний день существует несколько определений данного понятия. Ю.Н. Караулов под прецедентным текстом понимает высказывание, значимое для той или иной личности в познавательном и эмоциональном отношении и имеющее сверхличностный характер, т. е. хорошо известное широкому окружению данной личности; обращение к которому неоднократно возобновляется в ее дискурсе (Караулов 2004, 216). Другой ученый, Г. Г. Слышкин, расширяет содержание данного термина, определяя его как «...любую характеризующуюся цельностью и связанностью последовательность знаковых единиц, обладающую ценностной значимостью для определенной культурной группы» (Слышкин 2000, 22). В этом случае речь идет не только о широком окружении языковой личности, но и об узком круге людей (семье, компании друзей, студенческой группе), для которых использование конкретного текста является прецедентным, т.е. общеизвестным. Феномен прецедентности зачастую относят к явлению интертекстуальности, то есть реализации межтекстовых связей (Барт 1989, Глушак 2007, Золотухина 2008, Чернявская 2000), а в качестве главной особенности этих текстов считают их «...способность сохранить в свернутом виде достаточно большой объем информации» (Лисоченко 2007, 24), глубина восприятия и понимания которой зависит от фоновых знаний адресата и его готовности к ассоциативному мышлению. Зачастую источниками таких высказываний становятся тексты библейского происхождения, народного и индивидуального художественного творчества, изобразительного, музыкального, мультипликационного, кино- и др. видов искусства. Однако процесс превращения вышедших из данных источников высказываний в прецедентные фразы имеет свою специфику: вначале такие тексты являются полноценными цитатами, не имеющими широкого распространения и известности и требующие в связи с этим ссылки на первоисточник (с целью демонстрации уважения к чужому источнику), но впоследствии информативность и выразительность содержания данных высказываний позволяет адресантам обращаться к ним все чаще и чаще. В результате они начинают употребляться самостоятельно, без отсылки к источнику возникновения. Такое использование цитат (в широком понимании этого слова) зачастую называют скрытым цитированием (Валгина 2003). При этом в науке семантика данного понятия включает в себя и другое значение: использование приобретающей популярность цитаты (но еще не прецедентного высказывания) в качестве стилистического приема в целях придания тексту большей выразительности (Сидоренко 1995, 98), что обусловливает и педагогически оправданное введение данных высказываний в монологи учителя. Как показывает наш опыт наблюдений, учитель зачастую обращается к цитированию прецедентных текстов с целью украсить или аргументировать свой монолог, эмоционально разрядить сложную (или конфликтную) ситуацию, настроить 
школьников на активную деятельность, создать проблемную учебную ситуацию с целью активизировать их познавательный интерес, расширить культурный кругозор учащихся и т.д.

При этом все прецедентные высказывания, в том числе используемые в речи учителя, можно объединить несколькими признаками: а) общеизвестностью и массовой распространенностью; б) длительным сохранением содержания этих текстов в культурной памяти народа; в) неоднократной воспроизводимостью; г) отсутствием обязательной ссылки на источник; д) полифункциональностью, т.е. многозначностью использования данных текстов в различных, в том числе учебно-речевых, ситуациях. При этом жанровый репертуар прецедентных высказываний, применяемых учителем, может включать в себя как цитаты из художественных текстов, авторство которых установлено, то есть крылатые выражения («А судьи кто?..»; "Человек - это звучит гордо!»; "За что же, не боясь греха, Кукушка хвалит Петуха? За то, что хвалит он Кукушку» и др.), так и пословицы, поговорки, легенды, предания, байки, анекдоты, притчи и др.

Помимо собственно цитат и прецедентных высказываний, в репертуар дословных (цитируемых) репродуктивных фраз педагога следует включать и фрразы-клише (типа «Доброе утро», "До завтра», "Урок окончен», "Откройте учебник и прочитайте задание», "Ответьте на вопросы», «Запишите предложение» и др.). Они в точности воспроизводятся на основе устного педагогического образца и зачастую представляют собой традиционные педагогические требования, высказывания оценочного или этикетного характера. При этом некоторые педагогические требования могут иметь письменный источник, если их содержание основано на инструктирующем высказывании, взятом из учебника или учебного пособия («Перепишите текст, вставляя пропущенные буквы»). Эти цитаты имеют специфическое функциональное значение: связывают отдельные монологи учителя в единое целое, организуют деятельность учащихся на уроке и в целом превращают учебное занятие в единое, завершенное, целостное и связное поликодовое высказывание, имеющее все необходимые признаки текста как коммуникативного феномена.

Описанные выше разновидности цитат нередко являются интерактивными (внутренними) жанрами педагогических монологов, зачастую представляющих собой пересказы, основанные на изменении содержания первоисточников. Цитаты же в данных монологах выполняют комплексные педагогические задачи (обучающего, воспитательного и развивающего характера), превращая развернутое высказывание учителя в отвечающий интенциям урока текст.

Таким образом, можно отметить, что цитирование как процесс дословного воспроизведения содержания первоисточников является не менее востребованным феноменом в профессиональной практике педагога, наряду с пересказом, т.е. недословным воспроизведением чужой информации в педагогических целях. В комплексе профессионально оправданные явления цитирования и пересказа позволяют назвать речевую практику учителя репродуктивной, включающей в себя разнообразный жанровый репертуар. Цитаты, как правило, вводятся в речь учителя самостоятельно, с помощью глаголов-перформативов или как часть предложений в конструкциях с вводными словами, прямой или косвенной речью, реже с помощью клишированных фраз-скреп, если речь идет об объемном высказывании в виде притчи, предметной сказки, анекдота. Полное (в точности воспроизводящее содержание, структуру, композиционные и языковые особенности первоисточника) заимствование чужой информации, в том числе в образовательных целях, определяет систему жанровых форм дословных высказываний учителя, к которым можно отнести клишированные фразы (жанры), 
прецедентные тексты, собственно цитаты и эпиграфы. Уместность, т.е. оправданность, их использования на занятиях (учет условий сложившейся учебно-речевой ситуации, психологических и возрастных особенностей развития детей, предметных представлений учеников, следование канонам уважительного отношения к собеседникам и др.) помогает решать учителю комплекс педагогических задач, что позволяет назвать феномен цитирования профессионально значимым явлением в репродуктивной коммуникативной практике педагога.

\section{Использованная литература/ References}

АГРАНОВИЧ, Н. Б. (2006): Вторичные тексты в коммуникативно-когнитивном аспекте: автореф. дис. ... канд. филол. наук. М., 2006. 28 с.

АРБУЗОВА, В. Ю. (2007): Прецедентность в русском языке как лингвистический и культурный феномен: автореф. дис. ... канд. филол. наук. Елец, 2007. 24 с.

АРУТЮНОВА, Н. Д. (1999): Язык и мир человека. М.: «Языки русской культуры», 1999. 896 с. ISBN 5-7859-0027-0. БАБАЙЦЕВА, В. В., ЧЕСНОКОВА, Л. Д. (2006): Русский язык. Теория. 5-9 кл.: учебник для общеобразоват. учрежд. М.: Дрофа, 2006. 330 с. ISBN 978-5-3581-061

БАЛЯкОВА, Н. А. (2005): Чужое слово во внешней и внутренней речи: автореф. дис. ... канд. филол. наук. СПб, 2005. 22 c.

БАНнИКОВА, С. В. (2004): Прецедентность как лингвокультурный феномен: автореф. дис. ... канд. филол. наук. Тамбов, 2004. 24 с.

БАРТ, Р. (1989): Избранные работы: Семиотика. Поэтика. М.: Прогресс, 1989. 616 с. ISBN 978-5-01004408-4

БАХТИН, М. М. (1986): Проблема текста в лингвистике, филологии и других гуманитарных науках. Опыт философского анализа. Литературно-критические статьи. сост. С. Бочаров и В. Кожинов. М.: Художественная литература, 1986, с. 473-501.

ВАЛГИНА, Н. С. (2003): Теория текста: учебное пособие. М.: Логос, 2003. 280 с. ISBN 5-94010-187-0.

ГЛУШАК, Т. С., МИРСКИЙ, А. А. (2007): Интертекст и интертекстуальность In Дискурсивный континуум: текст - интертекст - гипертекст: материалы Всероссийской научной конференции. Самара: СамГпУ, 2007, c. 40.

ГОРДЕЕВА, Л. В. (2012): Чужая речь в коммуникативной практике учителя русского языка и литературы: диссертация на соискание ученой степени канд. пед. наук. Новокузнецк, 2012. 299 с.

ДЕМЕНТЬЕВ, В. В. (2000): Непрямая коммуникация и ее жанры. под ред. В. Е. Гольдина. Саратов: Изд-во Саратовского ун-та, 2000. 248 c. ISSN: 2219-8776.

ДЕСЯЕВА, Н. Д. (1995): Речь учителя русского языка в контексте урока: учебное пособие по спецкурсу. М.: «Прометей», 1995. 112 с.

золотухИНА, Е. Н. (2008): Интертекстуальность в современном русском языке. Русский язык в школе. 2008, № 5, c. 44-48.

ИСАЕВА, А. В. (2001): Функционирование прецедентных текстовых реминисценций в устной речи носителей русского языка: автореф. дис. ... канд. филол. наук. М., 2001. 24 с.

КАРАУЛОВ, Ю. Н. (2004): Русский язык и языковая личность. М.: Наука, 2004. 264 с. ISBN: 978-5-397-063784.

КлякИНА, Е. А. (2006): Обучение студентов-филологов приемам интерпретации научного текста в целях учебного общения: автореф. дис. ... канд. пед. наук. Ярославль, 2006. 24 с.

КОДУХОВ, В. И. (1957): Прямая и косвенная речь в современном русском языке. Ленинград: Учпедгиз, 1957. $10 \mathrm{c}$.

КОРОСТОВА, С. В. (1994): Способы передачи чужой речи. Русский язык в школе. 1994, № 5, с. 96-99.

КОСТОМАРОВ, В. Г., БУРВИКОВА, Н. Д. (1994): Как тексты становятся прецедентными. Русский язык за рубежом. 1994, № 1, с. 73-77.

ЛИСОчЕНКО, О. В. (2007): Риторика для журналистов: Прецедентность в языке и речи: учебное пособие 
для студентов вузов. Ростов-на Дону: Феникс, 2007. 318 с.

лУКИН, В. А. (2005): Художественный текст: основы лингвистической теории. Аналитический минимум. М.: Изд-во «Ось-89», 2005. 560 с. ISBN: 5-86894-978-1.

лытКИНА, И. В. (2003): Обучение студентов употреблению прецедентных текстов: автореф. дис. ... канд. пед. наук. М., 2003. 15 с.

МАКСИМОВА, Н. В. (2006): «Чужая речь» как коммуникативная стратегия: автореф. дис. ... канд. пед. наук. СПб, 2006. 44 с.

МЕЩЕРЯКОВ, В. Н. (2002): Как пересказывать произведения литературы, живописи, музыки: методические приемы и образцы. М.: Флинта: Наука, 2002. 272 с. ISBN: 978-5-89349-295-8.

МолодцОВА, С. Н. (1988): Способы передачи чужой речи. Прямая и косвенная речь. Русский язык в школе. 1988, № 32, с. 40-45.

МОСКВИН А. Ю., Большой словарь иностранных слов (2006) М.: ЗАО Центрполиграф, 2006. 816 с. ISBN: 59524-1479-6.

НАУМОВА, Е. О. (2003): Особенности функционирования прецедентных текстов в современном публицистическом дискурсе: автореф. дис. ... канд. филол. наук. Воронеж, 2003. 22 с.

Русский язык: учебник для 6 кл. общеобразоват. учрежд. М.Т. Баранов, Т.А. Ладыженская, Л.А. Тростенцова; науч. ред. Н.М. Шанский. М.: Просвещение, 2006-2010. 239 с.

СИДОРЕНКО, К. П. (1995): Скрытая цитата. Русский язык в школе. 1995, № 2, с. 98.

СлышкИН, Г. Г. (2000): От текста к символу: лингвокультурные концепты прецедентных текстов в сознании и дискурсе. М.: Academia, 2000. 128 c.

ЧЕРНЕЦ, Л. В., ХАЛИЗЕВ, В. Е., ЭСАЛНЕК, А. Я. и др. Введение в литературоведение: учебное пособие. под ред. Л. В. Чернец. М.: Высшая школа, 2004, с. 477-488.

ЧЕРНЯВСКАЯ, В. Е. (2000): Интертекстуальность как текстообразующая категория в научной коммуникации: автореф. дис. ... докт. пед. наук. СПб, 2000. 49 с.

щУРИНА, Ю. В. (2004): Прецедентный текст в межкультурной коммуникации (на материале вторичных комических речевых жанров). Речевое общение: специализированный вестник. под ред. А. П. Сковородникова. Красноярск: Краснояр. гос. ун-т, 2004, вып. 5-6, с. 155-160.

\section{Профиль автора}

Любовь Викторовна Гордеева, кандидат педагогических наук, доцент кафедры русского языка и литературы фракультета филологии Новокузнецкого института (филиала) ФГБОУ ВО «Кемеровский государственный университет»

Научные интересы: коммуникативная культура педагога-филолога, речевая практика современников, жанры речи, теория и методика обучения русскому языку и литературе, школьное и вузовское филологическое образование.

E-mail: lyuba.gordeeva.85@mail.ru

Место работы: Новокузнецкий институт (филиал) ФГБОУ ВО «Кемеровский государственный университет», факультет филологии, кафедра русского языка и литературы.

Адрес: г. Новокузнецк, ул. Радищева, д. 34, кв. 21, индекс: 654086, Россия.

\section{Author's profile}

Lyubov Viktorovna Gordeeva, candidate of pedagogical Sciences, associate Professor of the Department of Russian language and literature, faculty of Philology, Novokuznetsk Institute (branch) Kemerovo state University Research interests: communicative culture of a philologist, speech practice of contemporaries, genres of speech, theory and methods of teaching Russian language and literature, school and University philological education.

E-mail: lyuba.gordeeva.85@mail.ru

Place of work: Novokuznetsk Institute (branch) Kemerovo state University, faculty of Philology, Department of Russian language and literature.

Address: Novokuznetsk, 34 Radishcheva str., sq. 21, index: 654086, Russia. 